\title{
SAPROLEGNIOSIS EN TRUCHA ARCOIRIS (Oncorhynchus mykiss Walbaum) EN LA PISCICULTURA DE RIO BLANCO (V REGION-CHILE)
}

\author{
(Saprolegniosis in rainbow trout (Oncorhynchus mykiss Walbaum) \\ in "Rio Blanco" pisciculture,V Región-CHILE)
}

\author{
Valia M. Vivar Muñoz \\ Escucla de Ciencias del Mar,Universidad Católica de Valparaíso \\ Av. Altamirano 1480 Valparaiso, Chile.
}

Palabras clave: Saprolegniosis, Saprolegnia parasitica, trucha arcoiris

Key words: Saprolegniosis, Saprolegnia parasitica, rainbow trout

\section{RESUMEN}

En la Piscicultura de Rio Blanco (V Región) entre Abril, 1995 y Marzo 1996, se estudiaron los agentes responsables de saprolegniosis en trucha arcoiris y sus huevos, con el objetivo de caracterizar morfo-fisiológica y patogénicamente a los hongos del complejo Suprolegnia asociados a su cultivo.

Lospropágulos de dispersión füngicos (zoosporas). se obtwieron a partir de 2 estaclos econutricionales: "saprolirofo", aislados de muestras de agua de 5 sectores de la piscicultura, y "biotrofo" desde peces y huevos infectados, A las muestras de agua se les adicionó semillas de cáñamo como cebo, mientras que las hifas provenientes del estado biotrofo se cultivaron directamente en agar GY. La determinación taxonómica de los aislamientos se realizaron mediante análisis de las hifas $y$ de los órganos reproductivos, cultivados en semillas de cáñamo, mien-ras que, las caracteristicas fisiológicas se observaron en agar GY, a 10,20 y $30^{\circ} \mathrm{C}$, y con tres regimenes de luz, midiendose el lamaño de las colonias cada 2 t hr para determinar su crecimiento diario.

Desde las muestras de agua se aislaron 2 tipos de colonias que se diferenciaron pormorjologia yvelocidad de crecimiento. Los aislamientos se desarrollaron en las 3 temperaturas utilizadas aunque con distintas tasas de crecimiento.

Mediante una incisión subcutánea poco profinda en los peces, se demostró el poder patógeno de las zoosporas de las cepas estudiadas, subdividièndolas en tres grupos experimentales seguin su origen: BIOR $(=$ Biotrofos), SAPR (= Saprotrofos con colonias de crecimiento regular) y SAPI (= Saprotrofos con colonias de crecimiento irregular). Los resullados de patogenicidad indicaron que las cepas BIOR y SAPR fiteron patógenas, alcanzándo un $100 \%$ de morbilidad, mientras

\section{SUMMARY}

Within April 1995 and March 1996, the agents responsible for causing saprolegniosis on rainbow trouts and their eggs were studied in the pisciculture of Rio Blanco ( $5^{\circ}$ región), in order to get a morpho-physiological and pathogenical characterizalion of the fungi from the Saprolegnia complex, associated to their culture.

The zoospore were collected from 2 econutritional states "saprotrophic", isolated from water samples taken in 5 sectors of the pisciculture and "biotrophic" from infected fish and eggs. Water samples were added with hemp-seed as a bait while hypha resulting from biotrophic state were directly cultived in GY agar:

The taxonomic delermination of isolates was carried out by means of the analysis of hypha and the reproductive organs cultured in hemp-seed, whereas physiological characteristics were studied in GY agar at 10,20 and $30^{\circ} \mathrm{C}$ and under three lighting conditions, the size of colonies being measured each $24 \mathrm{hr}$ to ascertain their daily growth.

Two kinds of colonies, wich differed one fiom the other in morphology and growth, were isolated from the water samples. Isolations were developed under the three prescribed temperatures yet with different rates of growht

By making a shallow subcutaneous incision in the fish, the pathogenic capacily of zoospore from the strain under study was shown, subdividing them into 3 experimental groups according to their origin: $B I O R, 1=$ Biotrophics), SAPR (= Saprotrophics with regular grown colony) and SAPI (= Saprotrophics with irregular grown colonv). The resulls of pathogenicity revealed that BIOR and SAPR strain were pathogenic reaching a 100\% morbility, whereas SAPI strain behaved like saprolrophic (0-I\% morbility). 
las cepas SAPI, se comportaron como saprotrofas (morbilidad entre $0-1 \%$ ).

Como caracter concluyente en la identificación final de los hongos, se utilizó su capacidad de crecer a $30^{\circ} \mathrm{C}$. Todas las cepas aisladas se clasificaron como Saprolegnia parasitica Coker:

\section{INTRODUCCION}

El término saprolegniosis, se emplea para designar una infección fúngica (micosis) producida por una amplia variedad de hongos. pertenecientes a los géneros, Achlya, Aphanomyces, Leptomitus, Pythium y Saprolegnia. La mayoria de ellos pertenecen al Orden "Saprolegniales", Clase Oomycetes (Scolt y O'Bier. 1962: Singlial et al, 1987; Willoughby, $1978 \mathrm{Xu} \mathrm{cl} \mathrm{al,} \mathrm{1990;} \mathrm{Rand} \mathrm{y} \mathrm{Munden,}$ 1993a; Rand y Munden, 1993 b). Muchos de estos Oomycetes son capaces de infectar peces de habitat marino, estuarino o dulceacuícola. en todas sus etapas de vida, huevos, larvas, juveniles y adultos (Scott y O'Bicr, 1962: Xu y Rogers, 1991; Rand y Munden, 1993 b).

La saprolegniosis de los pecestelcóstcos se considera como una infección sccundaria (oportunista) a una enfermedad viral o bacteriana o como consecuencia de una lesión en la superficie del pez. (Richards y Pickering. 1978; Willougby, 1978; Xu et al,, 1990). En los peces salmonídeos, tales como Salvelimus alpinus, Salmotrutta, Salmo salar, Oncorhynkus mykiis, se ha encontrado que. por lo general, el agente causal de estas micosis corrcsponde a hongos del género Saprolegnia (Richards y Pickering. 1978; Papatheodorou et al., 1981; Willoughby. 1978). Las especies inás frecuentemente citadas corresponden a "Saprolegnia parasitica Coker" y "Saprolegnia diclina Humprey" (Scott y O'Bicr. 1962; Singhal et al, 1987. Willoughby. 1978; Bullis y Noga. 1990: Hatai y Hoshiai, 1993; Dieguez-Uribeondo et al,, 1994).

Debido a su naturalcza saprótrofa los hongos responsables de las micosis en peces son abundantes en el medio ambiente acuático, siendo ćste la principal fucnte de infección. En algunas cepas potencialmente patógenas los mismos peces infectados son considerados como vectores. El modo de transmisión de la enfermedad es directa. cl hongo pasa del estado saprótrofo al cstado biótrofo, via esporas, cuando encuentra un huésped receptivo (Kinkelin et al, 1985).

Para poder determinar el agente causal, es necesario aislarlo desde el animal enfermo y obtener sus estructuras reproductivas en un medio de cultivo apropiado, los anamorfos del hongo son utilizados para definir los géneros, y los telcomorfos para las especies (Bullis y Noga, 1990): Debido a que las estructuras scxuales de Saprolegnia parasitica Coker son morfológicamente similares a las observadas en el estado saprotrofo de la
As a conclusive measure in the final identification of the fungi, their ability to grow at $30^{\circ} \mathrm{C}$ was used. Every isolated strain was classified as Saprolegnia parasitica Coker.

especic "Saprolegnia diclina Humprey", se ha optado por utilizar el término "Complejo Saprolegnia" para designar al complejo formado por S.parasitica $-\boldsymbol{S}$. diclina (Singhalet al, 1987; Willoughby, 1978; DieguezUrebeondo et al., 1996). Este complejo se caracteriza por presentar un crecimiento masivo de delgados filamentos de color blanco-gris, semejante a molas de algodón en la superficie de piel, aletas y agallas de los peces (Papatheodorou et. al,198I; Kinkelin et al, 1985; Richard y Pickering, 1978; Willoughby, 1978).

Los hongos responsables de las saprolegniosis son cosmopolitas, sin embargo, la distribución de las especies está controlada principalmente por la temperatura del agua, mostrando una clara fluctuación estacional, con un másimo de especies en primavera y otoño (Papatheodorou. 1981; Hubcrt, 1982). En Chile las micosis de peces de cultivo y sus huevos se han observado desde la V hasta la XI Regiones, por lo general se denominan como saprolegniosis, aunque no se hayan identificado la o las especies de hongos responsables. El diagnóstico de estas micosis es muy delicado, pucs algunas cepas, en el pez o aisladamente, son incapaces de crecer y, en consecuencia, imposibles de diferenciar de las abundantísimas especies saprotrofas presentes en el medio acuático (Kinkelin,et al.. 1985).

En esta investigación se realizó una caracterización morfo-fisiológica y patogénica de hongos del "complejo Saprolegnia" asociadas al cultivo de trucha arcoiris (Oncorhynchus mykiss Walbaum), a partir de su estado biótrofo y saprótrofo en la piscicultura de Río Blanco, V Región, Chile.

\section{MATERIALES Y METODOS}

Las muestras fucron tomadas en la Piscicultura de Rio Blanco, perteneciente a la Universidad Católica de Valpararaíso, este centro de cultivo se encuentra ubicado en la provincia de Los Andes, $45 \mathrm{Km}$. al Este de la ciudad de Los Andes, a una altura aproximada de 1420 m.s.n.m.

1.- Obtención y cultivo del hongo a partir de muestras de agua (estado saprotrofo).

Las muestras se tomaron mensualmente, entre abril (1995) y marzo (1996) con temperaturas que fluctuaron entre 5 y $15^{\circ} \mathrm{C}$, en cinco sectores de la Piscicultura que 
corresponden a :

- Estanque de tierra (E.T.)

- Estanque de PVC (E.P.)

- Estanque de cemento (E.C.)

- Sala de incubación (S.I.)

- Toma de agua (T.A.)

En cada uno de cstos lugares se tomaron 3 muestras, las que fueron colcctadas a una profundidad de $30 \mathrm{~cm}$, con botcllas estériles de $30 \mathrm{ml}$, en una rcgión cercana a la orilla o borde de los estanques. Se llenaron con $25 \mathrm{ml}$ de agua y se taparon, trasladandose al laboratorio en el transcurso de 4-5 horas. Una vez allí se vertió su contenido en recipientes con $10 \mathrm{ml} \mathrm{de}$ agua destilada estéril, posteriormente, como cebo, se adicionó 3 mitades de semillas de cáñamo esterilizadas en autoclave.

A los 15 días, las semillas colonizadas, se scmbraron en placas con agar GY, consistente en I() g de glucosa, $2,5 \mathrm{~g}$ de cxtraclo de levadura y $15 \mathrm{~g} \mathrm{de}$ agar en $1000 \mathrm{ml}$ de agua destilada (Hatai y Hoshiai, 1992a). El pH del medio se reguló en 0.5 y para inhibir el crecimiento bacteriano se adicionó al medio 500$) \mu \mathrm{g} / \mathrm{mI}$ de penicilina $\mathrm{G}$ y sulfato de estreptomicina.

Posteriormente, se incubaron a tcmpcratura anbiente $\left(16-22^{\circ} \mathrm{C}\right)$, por un periodo de 5 a 10 dias. bajo un régimen de luminosidad normal. A cada una de las muestras obtenidas se les midió. el tiempo requerido para colonizar las semillas de cáñamo y el diámetro que alcanzaron las colonias en éstas a los 15 días de cultivo. En las placas con agar GY se observó la morfología de la colonia y se registró el tiempo requerido para cubrir completamente la superficie del agar $(9 \mathrm{~cm}$ diámetro).

2.- Obtención y cultivo de los hongos acuáticos a partir de peces y huevos infectados (estado biotrófo)

Peces: Mensualmente se tomaron muestras de 3 especimenes vivos de trucha arcoiris. (Oncorhynchus mykiss Walbaum) con síntomas de saprolegniosis, lo que se manifestó por la presencia de manchas algodonosas en la picl (Xu y Rogers, 1991).provenientes de los estanques de cultivo, tierra y PVC. Se seleccionaron estos cstanques porque en ellos se observó la mayor incidencia de peces con micosis.

De cada pez se retiraron fragmentos de micclio desde cl centro y bordes de la lesión formándosc asi un pool de muestras (por pez), estas se lavaron con agua destilada estéril y se secaron, posteriormente se pusicron en 3 placas Petri con agar GY y se mantuvicron a temperatura ambiente hasta el desarrollo de las colonias (4 dias).

De los mismos estanques se seleccionaron tres peces aparentemente sanos, sin signos de micosis, a éstos se Ics realizó un raspado de escamas y mucus superficial el que se inoculó en Placas de Petri con agar GY.

Huevos:Durante los meses de Junio, Julio y Agosto se tomaron muestras de 9 huevos sanos y nueve huevos infectados (por mes), los que se lavaron, secaron y pusieron directamente sobre placas de Petri con agar GY (Scott y O'Bier, 1962). Las placas se mantuvieron a temperatura ambiente $\left(16-22^{\circ} \mathrm{C}\right)$, hasta el crecimiento de las colonias (4 días) .

A los 4 dias dcincubación en Agar GY a temperatura ambientey régimen de luz normal, se registróla morfologia y crecimiento de las colonias obtenidas del micelio proveniente de los peces y huevos infectados.

\section{3.- Obtención de cepas puras a partir de los estados saprótrofo y biótrofo y mantención de los hongos.}

Cuando las colonias cubrieron las placas con agar GY, se removicron algunas hifas, se transfirieron a nuevas placas con agar, y sc incubaron a temperatura ambiente. Al cabo de tres dias, de la periferia de las colonias se sacó un cuadrado $(3 \times 3 \mathrm{~mm})$ de agar con hifas, el que se transfirió a una nucva placa con agar.

Con el fin de obtener cultivos puros, la operación anterior se repitió cinco veces cuidando que las hifas contenidas en el bloque de agar fueran de reciente aparición. Los cultivos asi obtenidos se consideraron cultivos puros y fueron traspasados a tubos con agar inclinado. Se mantuvicron a $5^{\circ} \mathrm{C}$, transfiriendose mensualmente.

\section{4- Caracterización de las cepas aisladas (Saprotrofas y Biotrofas).}

Caracterización morfológica:Tanto para las muestras obtenidas desde las diversas fuentes de agua, como de aquellas aisladas de los peces y huevos infectados se obscrvó la morfologia de las hifas vegetativas, posteriormente se indujola formación de estructuras reproductivas, para lo cual, se sembró un inóculo de cada una de las cepas en placas con agar GY.

Al tercer día de cultivo a temperatura ambiente, 3 milades de semillas de cáñamo estériles se dispusieron sobre las colonias, cuando éstas se infectaron se transfirieron a placas con agua destilada estéril, seguida de una incubación por 5-10 dias a temperatura ambiente (16-22 ${ }^{\circ} \mathrm{C}$ ). Con el fin de observar el desarrollo de las estructuras reproductivas (asexuales y sexuales), se seleccionaron porciones de las hifas que fueron observadas al microscopio con(Lactofenol con azúl de algodón) y sin tínción .

Caracterización fisiológica: Seseleccionaron 40 colonias que fucron cultivadas en agar GY y sometidas a dos condiciones de temperatura $\left(10\right.$ y $20^{\circ} \mathrm{C}$ ). Para determinar 
si el régimen de luz influye en el crecimiento de las colonias, estas fueron incubadas bajo tres condiciones de luz (normal, iluminadas durante 24 horas yen oscuridad).

Con el fin de construir curvas de crecimiento radial de todas las cepas, se retiró un trozo de agar $(3 \times 3 \mathrm{~mm})$ con hifas proveniente de todas las placas donde se cultivaron las cepas originales, $y$ se sembraron en triplicado en placas con agar GY. El crecimiento de estas colonias se midió con un pie de metro cada 24 horas, hasta completar la superficie de las placas $(9 \mathrm{~cm})$ (Hatai y Hoshiai, 1992b).

Para el cálculo final se tomó un promedio con los valores registrados de tres mediciones.

\section{5.- Patogenicidad de las cepas aisladas}

Para probar la patogenicidad de los hongos aislados, se seleccionaron:

- 40 truchas arcoiris con un peso promedio de 100 $( \pm 12)$ g y una longitud de $21( \pm 2) \mathrm{cm}$.

-40 truchas arcoiris con un peso promedio de 10 $( \pm 2) \mathrm{g}$ y una longitud de $10( \pm 1) \mathrm{cm}$.

Con el fin de mantener controladas las condiciones de cultivo, los peces fueron trasladados desde la piscicultura de Río Blanco, hasta la Escuela de Ciencias del Mar en Valparaiso, donde se distribuyeron en estanques de experimentación con agua desclorada y filtrada. La densidad fue de $5 \mathrm{Kg} / \mathrm{m}^{3}$, la temperatura del agua de $17+1-2^{\circ} \mathrm{Cy}$ la aireación constante.

Después de un período de aclimatación de 15 días, los peces se prepararon desinfectándolos con una solución con antifúngico (verde malaquita), se anestesiaron con Benzocaina al $1 \%$, y para verificar que no presentaran daños visibles se examinaron bajo lupa binocular. Con un bisturí fino se realizó una herida subcutánea, poco profunda, de aproximadamente $1 \mathrm{~cm}$ de largo en ambos costados de los peces, a la altura de la aleta dorsal.

Para cada tamaño, las 40 truchas en estudio se dividieron en cinco grupos $(\mathrm{n}=8)$, como se enumera a continuación:

1.- Truchas infectadas con un inóculo proveniente de las cepas aisladas desde su estado biotrofo: BIOR,

2 y 3.- Truchas infectados con inóculos provenientes de las cepas recuperadas de las distintas fuentes de agua: SAPR y SAPI

4.- Peces que se mantuvieron en contacto con el inóculo, sin que se les practicara la herida:CONTROL 1

5.-Truchas a las que se les practicó la incisión pero que no fueron infectadas: CONTROL 2

De los peces que desarrollaron la infección, se tomaron muestras de los hongos y se cultivaron e identificaron según la metodologia anterior.

Debidoa que las zoosporas son losúnicos elementos capaces de producir la infección, para poder infectar a las truchas, fue necesario inducir su formación al cultivar los hongos en agua destilada. Una vez desarrollados los esporangios, fueron captados bajo microscopio invertido, y se extrajeron con ayuda de agujas de disección y micropipeta.

Para la infección, se tomó un inóculo de $0,5 \mathrm{ml}$, (aproximadamente 10000 zoosporas por $\mathrm{ml}$ ) y se distribuyó directamente en las heridas realizadas en la superficie de los peces, ayudando a su penetración con la aguja de disección (Singhal et al., 1987).

\section{6.- Identificación de las cepas}

La identificación de las cepas se efectuó en base a los resultados de la caracterización morfo-fisiológica. Se tomaron como carácteres con valor taxonómico: tipo de esporangios y su dehiscencia, tipo de oospora, posición y forma del oogonio, origen del anteridio, modo de adhesión del anteridio, tamaño de oogonios - oosporasy la capacidad para crecer a $30^{\circ} \mathrm{C}$, según los criterios de Seymur, (1970); Willoughby (1978); Papatheodorou (1981), Chien (1981), Hatai y Hoshiai (1992 y 1993), Dieguez-Uribeondo et al. (1996).

\section{RESULTADOS}

1.- Obtención y cultivos de los hongos a partir de muestras de agua (Estanques de cemento, PVC, tierra, sala de incubación y toma de agua)

Seaisló un total de 314 colonias de Saprolegniales, provenientes de las distintas fuentes de agua.

A los 15 días de cultivo en agua destilada, a temperatura ambiente, las semillas de cáñamo se cubrieron completamente de hifas, formando colonias de 1 a 2 $\mathrm{cm}$ de diámetro. En las semillas se originaron 2 tipos de hifas, unas poco ramificadas, de 30-80 $\mu \mathrm{m}$ de diámetro y otras ramificadas y delgadas (10-25 $\mu \mathrm{m}$ de diámetro). A partir de las primeras se generaron clamidosporas y esporangios del tipo saprolegniode, mientras que en las segundas se produjeron oogonios y anteridios. Al ser traspasadas a placas con agar GY, ambos tipos de hifas generaron colonias radiadas de aspecto algodonoso con hifas de 20 a $70 \mu \mathrm{m}$ de diámetro.

Al inocular las hifas desarrolladas en las semillas de cáñamo en agar GY, se observó que no todas las colonias presentaban la misma morfologia: el $55 \%$ pre-sentó una morfología que se clasificó como "regular", con un crecimiento radial y un micelio algodonoso adherido a la superficie del agar, alcanzando una altura de 0,3 a $0,7 \mathrm{~cm}$. Estas colonias se desarrollaron relativamente rápido, cubriendo la superficie de las placas a los 4 dias de cultivo ( $\mathrm{T}^{\circ}$ ambiente), en tanto el $45 \%$ restante presentó una 
morfología que se clasificó como "irregular", estas fueron levemente lobuladas, sus hifas mostraron una distribución espaciada, y un crecimiento más lento, requiriendo de 6 a 8 dias para cubrir completamente las placas, en estas últimas el micelio aćrco alcanzó incluso las tapas.

De los estanques de PVC y cemento, solo sc obtuvieron colonias con morfología regular, micntras que las restantes fuentes de agua generaron ambos tipos de colonias, predominando las irregulares en sala de incubación y toma de agua, en esta última se aisló un $84 \%$ de éstas, las que se aislaron de todos los muestreos realizados, mientras que en el estanque de tierra solo se registró un 39\% de estas colonias ( 5 de los 12 muestreos).

Si bien las colonias "regulares" se aislaron durante todo el año, se obscrvó una mayor frecuencia en Julio y Septiembre, meses en los que se registró la menor temperatura $\left(5.3\right.$ y $\left.7.5^{\circ} \mathrm{C}\right)$. Las "irregulares" se aislaron preferentemente en los meses de Enero y Noviembre, con temperaturas de $10.8^{\circ}$ y $15^{\circ} \mathrm{C}$ respectivamente.

2.- Obtención y cultivo a partir de reces y huevos infectados (Biotrofo).

Todas las muestras obtenidas desde hueros y peces infectados generaron colonias algodonosas. que al ser traspasadas a placas con agar $\mathrm{GY}$ mostraron una morfologia similar a las clasificadas como "regular. Estas colonias presentaron filamentos poco ramificados de $20-60 \mu \mathrm{m}$ de diámetro.

Independientemente de su origen, estas colonias alcanzaron al cuarto día de cultivo en agar GY, a temperatura ambiente, diámetros entre 7,5 y $8 \mathrm{~cm}$.

Las muestras obtcnidas desde la piel, mucus $y$ escamas de peces que no presentaban signos de saprolegniosis y los huevos sanos, no generaron colonias.

\section{Obtención de cultivos puros y mantención de las cepas aisladas.}

Dependiendo de la morfologia del micelio aćreo en el medio de cultivo (regular eirregular), se seleccionaron $32(1: 1)$ cepas provenientes de las fuentes de agua (saprótrofas) , y 8 de origen biolrofo, las que se encuentran en el laboratorio de cultivo de peces de la Escuela de Ciencias del Mar, Universidad Católica de Valparaiso.

\section{4.- Caracterización de las cepas aisladas} grupos:

Las cepas scleccionadas se dividieron en tres

1, SAPR, corresponde a las cepas recuperadas a partir de las fuentes de agua que en agar GY mostraron una morfologia regular (cemento, PVC, toma de agua, tierra y sala de incubación)

2. SAPI, cepas provenientes de las fuentes; toma agua, estanque de tierra y sala de incubación, que al ser traspasadas a agar GY mostraron un patrón de crecimiento irregular.

3. BIOR, cepas provenientes de peces y huevos infectados, que presentaron un aspecto regular sobre el medio de cultivo.

\section{Caracterización morfológica:}

\section{SAPR. (saprotrofo con crecimiento regular)}

a) Hifas vegetativas. Presentaron ramificaciones espaciadas y alcanzaron un diámetro promedio de 20-45 $\mu \mathrm{m}$ ( $90 \mu \mathrm{m}$ en la base). A los 3 dias de cultivo en semillas de cáñamo se formaron abundantes clamidosporas, en posición: terminal, intercalar, lateral o en cadena. A partir de ellas se originaron oogonios y esporangios.

b) Esporangios. Terminales,con proliferación interna, filiformes o fusiformes, de 200 a $550 \mu \mathrm{m}$ de largo por 40-65 $\mu \mathrm{m}$ de ancho. Las esporas se liberaron cerca de 12 horas despućs de formada la papila de descarga, la salida tuvo una duración de aproximadamente $45 \mathrm{seg}$, las zoosporas ( 15 y $25 \mu \mathrm{m}$ de diámetros) se liberaron de a una y se alejaron rápidamente del esporangio.

c) Oogonios. Se visualizaron entre los 15 y 21 dias de ser inducidos, presentaron una posición terminal, lateral e intercalar, por to general piriformes, pero también , filiforme, doliforme o globosos, alcanzando diámetros de 50 a $110 \mu \mathrm{m}$ y un largo de 75 a $200 \mu \mathrm{m}$.

d) Oosporas. De forma redondeada, 15 a $37 \mu \mathrm{m}$. de diámetro céntrica o subcéntrica, completando totalmente el oogonio, en un número que fluctuó entre 1 y 30 .

e) Anteridios. Preferentemente diclinos, observándose de 1 a + células anteridiales sobre los oogonios.

\section{SAPI (Saprotrofo con crecimiento irregular)}

Estas cepas se caracterizaron por presentar un crecimiento lento en agar GY, las colonias desarrolladas presentaron un aspecto algodonoso con hifas esparcidas, moderadamente ramificadas, con un diámetro promedio de $40 \mu \mathrm{m}$ (20-I00 $\mu \mathrm{m})$. AI ser culcivadas en semillas de cáñamo, generaron dos tipos de hifas: unas muy ramificadas, densasy delgadas $(15-25 \mu \mathrm{m})$ y otras, menos ramificadas y más gruesas $(40-80 \mu \mathrm{m})$.

Losesporangios, midieron de $150-500 \mu$ m de largo por $18-70 \mu \mathrm{m}$ de ancho y las zoosporas alcanzaron hasta $18 \mu \mathrm{m}$ de diámetro. Las clamidosporas fueron escasas, de forma irregular y no se observó que generaran csporangios ni oogonios.

Los oogonios fueron abundantes, midieron de 35 a 
$150 \mu \mathrm{m}$ de diámetro, generalmente laterales, aunque también se encontraron algunos terminales e intercalares. Oogonios sésiles o pedunculados $(0-400 \mu \mathrm{m})$, ocasionalmente se observaron oogonios en cadenas. Por lo general, presentaron forma esférica, piriforme $o$ doliformes (los intercalares). Frecuentemente se observaron oogonios inmaduros. Las oosporas fueron esféricas, céntricas o subcén-tricas, con un diámetro que varió entre 17 y $35 \mu \mathrm{m}$. Se observaron escasos anteridios monoclinos y diclinos.

\section{BIOR. (Biotrofo con crecimiento regular)}

Las hifas vegetativas en cultivo, poco ramificadas, con diámetros de 15 a $60 \mu$; en semillas de cáñamo alcanzaron hasta $100 \mu \mathrm{m}$ en la base.

Clamidosporas abundantes, terminales, intercalares o en cadena, de forma irregular por lo general alargadas, a partir de ellas se generaron esporangios y oogonios.

Esporangios abundantes (a 10 y $20^{\circ} \mathrm{C}$ ), con forma alargada, claviforme y filiformes, de 150 a $450 \mu \mathrm{m}$ por 20 a $70 \mu \mathrm{m}$ de diámetro, en posición terminal e intercalar; en estas ocasiones las esporas se liberaron a través de un orificio de descarga lateral. Zoosporas abundantes, hasta $20 \mu \mathrm{m}$ de diámetro $(9-20 \mu \mathrm{m})$.

Oogonios, abundantes, sobre hifas delgadas (20$40 \mu \mathrm{m}$ ) lateraleso terminales, de forma esféricay piriforme, con diámetros de 30 a $300 \mu \mathrm{m}$, algunas veces fueron intercalares, en cuyo caso midieron hasta $380 \times 70 \mu \mathrm{m}$, con numerosas oosporas.

Oosporas esféricas con un promedio $20 \mu \mathrm{m}$ de diámetro, la mayoría de ellas céntricas, aunque también se observaron algunas subcéntricas. Dentro del oogonio se encontraron de 1 a 50 oosporas. Anteridios diclinos, o monoclinos del tipo andrógino e hipógino.

\section{Caracterización fisiológica:}

Como todas las cepas seleccionadas mostraron similares incrementos en diámetro al ser cultivadas con luz constante, oscuridad o bajo un régimen de luz normal, las curvas y tasas de crecimiento se determinaron con un régimen de luminosidad normal.

$\mathrm{Al}$ ser cultivadas a $10^{\circ} \mathrm{C}$ las colonias que presentaron menor crecimiento, correspondieron a las provenientes de una morfología irregular. Entre las que alcanzaron mayores diámetros a las 96 horas de cultivo, se ubicaron las provenientes del estado biotrofo.

A los $20^{\circ} \mathrm{C}$ las colonias de morfología regular fueron las que alcanzaron un mayor incremento en diámetro entre las 24 y 96 horas de cultivo ( desde 1,5 hasta 8,2 $\mathrm{cm}$ ). Sin embargo, a diferencia de lo que ocurrió a $10^{\circ} \mathrm{C}$, las colonias de morfologia irregular presentaron mayores incrementos.
Todas las colonias que se desarrollaron, fueron capaces de crecer, a $30^{\circ} \mathrm{C}$, aunque con crecimientos inferiores a los obtenidos con las temperaturas anteriores (Fig. 1).

En lo que respecta a los tiempos requeridos para la formación de estructuras reproductivas seobservó que, por lo general, se requiere de menor tiempo a 10 que a $20^{\circ} \mathrm{C}$.

Fig1. Diámetro de las colonias a las $96 \mathrm{~h}$ de cultivo en agar $\mathrm{GY}$ a $10-20-30^{\circ} \mathrm{C}$.

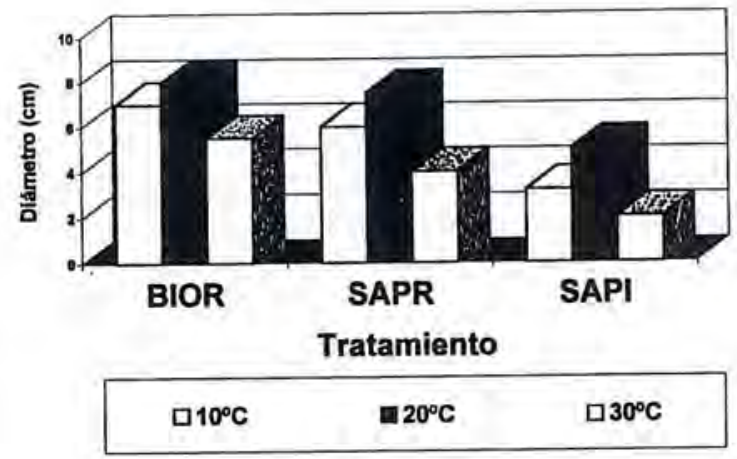

Los esporangios se visualizaron entre los 12 y 15 días a $10^{\circ} \mathrm{C}$ y entre los 21 y 28 días a $20^{\circ} \mathrm{C}$. En el caso de las estructuras sexuales, se requirió un mínimo de 26 y 58 dias a 10 y $20^{\circ} \mathrm{C}$ respectivamente. Las cepas irregulares requirieron más tiempo que las regulares para generar estructuras sexuales a $10^{\circ} \mathrm{C}$, en cambio a $20^{\circ} \mathrm{C}$ las cepas regulares requirieron de más tiempo (Tab,1).

Tabla 1: Tiempo promedio requerido para la formación de estruçturas reproductivas a 10 y $20^{\circ} \mathrm{C}$

\begin{tabular}{|l|c|c|c|}
\hline \multicolumn{4}{|c|}{ ESPORANGIOS OOGONIOS } \\
\hline ORIGEN & T$^{\circ}$ C & Tiempo días & Tiempo días \\
\hline & 10 & $12 \pm 2$ & $27 \pm 3$ \\
BIOTROFO & 20 & $25 \pm 3$ & $74 \pm 7$ \\
SAPROTROFO & 10 & $15 \pm 2$ & $26 \pm 3$ \\
REGULAR & 20 & $21 \pm 2$ & $68 \pm 6$ \\
SAPROTROFO & 10 & $18 \pm 3$ & $30 \pm 4$ \\
IRREGULAR & 20 & $28 \pm 3$ & $58 \pm 2$ \\
\hline
\end{tabular}

5.- Patogenicidad de los hongos aislados

Bioensayo en peces de $100 \mathrm{~g}$. BIOR (Biotrofo regular). Los primeros signos de 
Tabla 2: Resultados del Bioensayo

\begin{tabular}{|l|cc|cc|cc|cc|}
\hline Tamaño peces & $10 \mathrm{~g} \quad 100 \mathrm{~g}$ & $10 \mathrm{~g} \quad 100 \mathrm{~g}$ & $10 \mathrm{~g}$ & $100 \mathrm{~g}$ & $10 \mathrm{~g}$ & $100 \mathrm{~g}$ \\
\hline & $\begin{array}{c}\text { Tiempo (días) } \\
\text { inicio aparición } \\
\text { de síntomas }\end{array}$ & $\begin{array}{c}\text { Tiempo (días) en } \\
\text { aparecer } \\
\text { primeros muertos }\end{array}$ & $\begin{array}{c}\% \text { de Peces } \\
\text { Infectados }\end{array}$ & $\begin{array}{c}\% \text { de Mortalidad } \\
\text { a los } 30 \text { días } \\
\text { de ensayo }\end{array}$ \\
BIOR & 2 & 20 & 3 & 25 & 100 & 100 & 100 & 25 \\
SAPR & 5 & 25 & 9 & - & 100 & 100 & 87,5 & 0 \\
SAPI & 22 & - & - & - & 12,5 & 0 & 0 & 0 \\
CONTROL 1-2 & - & - & - & - & 0 & 0 & 0 & 0 \\
\hline
\end{tabular}

infección, se manifestaron a los 20 días de contacto con el inóculo por la presencia de hifas alrededor de las heridas inferidas a los peces, 2 de los 8 peces infectados murieron al cabo de 25 dias.

SAPR (Saprotrofo regular). Los primeros síntomas de saprolegniosis se observaron a 10525 días de inoculación, el segundo caso se registró a los 27 días. A los 30 dias de inoculación todos los peces presentaron signos de infección en el sitio de producida la lesión y sus alrededores, no se registraron mortalidades durante los 30 días de experimentación (Tab.2).

SAPI(Saprotrofo irregular). Hasta los 30 días de producida la inoculación no se observó síntomas de saprolegniosis en ninguno de los peces infectados.

Control 1 y 2 (Peces heridos sin infectar y Peces $\sin$ herida).No se observó signos de micosis en ninguno de los peces bajo estas condiciones (Tab.2).

\section{Bioensayo en peces de $10 \mathrm{~g}$.}

BIOR (Biotrofo regular). Los primeros signos de micosis se observarona los 2 dias de efectuada la infección. A los 10 días se registró una mortalidad del $100 \%$. Los peces estaban completamente cubiertos por las hifas (Tab.2).

SAPR (Saprotrofo regular). Inicialmente la colonización fue más benigna, los peces mostraron leves signos de micosis a los 5 dias de contacto con las zoosporas y la primera muerte se observó a los 8 dias. El $87,5 \%$ de los peces murieron cubiertos por hifas a los 15 dias de realizada la infección.

SAPI (Saprotrofo irregular). Durante los 30 días de experimentación, solo se detectaron sintomas leves de micosis en un pez, las hifas algodonosas se observaron en los bordes de la lesión. No se registraron mortalidades.

CONTROL 1 y 2. (Peces heridos sin infectar y peces $\sin$ herida). No se observaron signos de micosis ni de mortalidaddurante el período de experimentación (Tab.2).

La infección causadas en los peces por las cepas patógenas son similares, se inició en el sitio en que se produjo la lesión y posteriormente se expandieron hacia las áreas circundantes. El 100\% de los peces pequeños $(10 \mathrm{~g})$ manifestaron la infección entre los 2 y 5 dias, las hifas que se observaron a simple vista, se extendieron rapidamentey llegaron a cubrir completamente a los peces al cabo de 3 a 9 días, provocándoles la muerte.

Todos los peces de $100 \mathrm{~g}$ inóculados con estas cepas se infectaron, en la mayoria de ellos las hifas se circunscribieron a la periferia de la lesión. Los peces del grupo SAPR, desarrollaron la infección pero no presentaron mortalidades, sin embargo, con la cepa BIOR la lesión se extendió hacia otras regiones del cuerpo. En 2 de los peces infectados las hifas se desarrollaron sobre las branquias provocándoles la muerte entre los 25 y 30 días de experimentación. En cambio solo uno de los peces inóculados con el grupo SAPI mostró signos de infección, a los 22 dias se observó la presencia de hifas en los bordes de la herida, sin que las hifas se extendieran hacia otras áreas. Hasta los 30 dias la infección no continuó su evolución.

Los hongos recuperados a partir de los peces infectados artificialmente, correspondieron en sus características morfolisiológicas con las cepas inoculadas.

\section{6.- Identificación de las cepas}

Todas las cepas aisladas fueron capaces de generar zoosporangios con deshicencia saprolegnioide y proliferación interna, con lo que se comprobó que correspondían al género Saprolegnia.

Las cepas de hongos aisladas se caracterizaron por formar oogoniosy anteridios a 10 y $20^{\circ} \mathrm{C}$. En el primer caso requirieron de algunas semanas y en el segundo, fue necesario mantener las colonias en cultivo en semilla de cáñamo, por un periodo de 1 a dos meses. Los oogonios presentaron de 1 a 30 oosporas céntricas y subcéntricas con diámetros de 18 a $29 \mu \mathrm{m}$.

Al contrastar las características morfológicas, fisiológicas y patogénicas estudiadas, (que se resumen en la 
Tabla 3) con la literatura revisada (Seymur, 1970; Willoughby, 1978; Papateodorou, 198; Chien, 1981; Hatai y Hoshiai, 1992 y 1993; Dieguez-Uribeondo et al.,1996), consideramos que las 42 cepas aisladas pertenecen a la especie Saprolegnia parasitica Coker.

\section{DISCUSION}

La saprolegniosis, há constituido una amenaza en los cultivos piscicolas de agua dulce, y a la fecha existen múltiples reportes de esta enfermedad en cuerpos de agua y pisciculturas del Hemisferio Norte (Europa, Norte América, Japón), (Scott y O'Bier, 1962; Neish, 1970; Willoughby, 1978; Papatheodorou, 1981; Wood et al, 1986; Chien, 1987; Hatai y Hoshiai, 1992a, b; Rand y Munden, 1993. Yuasa y Hatai, 1994). En tanto en el Hemisferio Sur, la información sobre su incidencia es más restringida, se ha reportado en Australia sobre Nematolosa erebi (Puckridge, 1991), en Brasil en diferentes especies de carpas cultivadas (Figueida y' Ceccarelli, 1991), en Venezuela constituye uno de los r incipales agentes responsables de parasitosis en peces a . cultivo (Conroy y Hernández, 1989) y en Chile se presenta en las pisciculturas (agua dulce) donde ataca preferentemente a los salmónidos en etapa de reproducción y a sus huevos.

Los estudios realizados en nuestro pais se han enfocado principalmente en la prevención y tratamiento de los huevos infectados (Helena, 1994; Mendoza, 1994; Bernal, 1996). En la piscicultura de Río Blanco las mortalidades de las ovas fluclúan entre un 15 a un $25 \%$ (Bernal, 1996), y durante el transcurso de esta investigación (julio-agosto,1996) se observó que las ovas alcanzaron una mortalidad del $21 \%$. Los huevos infectados, frecuentemente se encontraron formando masas compactas, constituidas por hifas, huevos muertos, restos de huevos muertos y sedimento. En las ocasiones en que estas masas no pudieron ser eliminadas, (período de ova verde) el micelio se desarrolló y se extendió hacia los huevos vivos, llegando a cubrirlos completamente hasta conducirlos a la muerte, cuando las condiciones de cultivos no fueron las apropiadas, (exceso de materia orgánica en el agua y/o problemas de flujo del agua) la infección se extendió a toda una bandeja de incubación, provocandoles la muerte. Según Gajduesek y Rubcov (1985), la muerte del embrión sobreviene debido a que el micelio cubre la superficie de los huevos impidiéndoles el intercambio de gases. Además, la infección genera una disminución del glucógeno y por ende, una baja disponibilidad de glucosa, impidiendo que el embrión pueda llevar a cabo el melabolismo oxidativo (Timeyko, 1992).

La mayoría de los autores que han estudiado la saprolegniosis en huevos de peces, están de acuerdo con el hecho que ésta sólo se desarrolla a partir de huevos muertos (Smith y O'Bier, 1962; Wood et al 1986; Gajduesek y Rubcov; 1985; Timeyko, 1992). Las zoosporas son atraídas quimiotácticamente hacia los huevos muertos y, ayudadas por la formación de un material adhesivo, son capaces de asentarse, germinar y desarrollarse (Beakes y Burr, 1983). Aún cuando en el transcurso de esta investigación, se registró la presencia de zooporas de Saprolegnia en las bateas de incubación, no se observó micosis en los huevos vivos, aunque si, colonización sobre los huevos muertos (blancos), probablemente, debido a que éstos constituyen un buen sustrato para el asentamiento y desarrollo fúngico. Para constatar si las zoosporas de las cepas aisladas eran capaces de infectar huevos vivos, se realizó un ensayo (técnica no considerada en materiales y métodos) en el cual ástos fueron cultivados en un medio al que se le adicionó esporas y esporangios de las cepas aisladas, los huevos se mantuvieron en esie medio por un período de 30 dias sin que se manifestara la infección. Esta observación difiere con los resultados obtenidos por Lartseva y Dudka (1990), quienes encontraron que $\boldsymbol{S}$. parasitica y $\boldsymbol{S}$. ferax fueron capaces de infectar a huevos vivos de esturión, aún cuando éstos pudieron liberar enzimas que les otorgaron mayor resistencia a la infección. Rand y Munden (1993a), demostraron experimentalmente que las zoosporas de $S$. diclina son atraidas hacia la membrana de huevos vivos de Salvelinus fontinalis, en donde se adhieren y germinan. Ellos postularon que la invasión de los huevos se realiza por una combinación entre el efecto de enzimas extracelulares y presión mecánica.

Al contrario de lo que ocurre en pisciculturas Japonesas (Hatai y Hoshiai, 1993), Escocesas (Bruno y Stamps, 1987) y Españolas (Dieguez-Uribeondo et al, 1994), en la de Río Blanco no observamos mortalidades masivas de alevines, probablemente debido a que estos peces no sufren los típicos cambios morfofisiológicos que ocurren en otras especies de salmónidos durante esta etapa de su vida (esmoltificación). No obstante, esporádicamente se observó la infección en los alevines de trucha durante el transcurso del año, lo que podria ser atribuído al estrés que sufren durante las operaciones de: separación por tamaño y sexo, transporte, desdoble, alimentación o por factores ambientales tales como baja calidad del agua 0 cambios bruscos de temperatura (Bernal, 1996).

En todos los muestreos realizados (abril-marzo) se pudo verificar la presencia de zoosporas en las distintas fuentes de agua analizadas, sin embargo, la presencia de

Al comparar tasas de crecimiento, morfología de las colonias y poder patógeno de las cepas, se pudo constatar que las cepas obtenidas desde el estado biotrofo, presentaron una morfología regular, similares rangos de crecimiento a las tres temperaturas estudiadas y alto poder 
Tabla 3: Resumen de las características observadas en las cepas estudiadas

\begin{tabular}{|c|c|c|c|}
\hline & SAPR & SAPI & BIOR \\
\hline $\begin{array}{l}\text { HIFAS: } \\
\text { Diámetro }(\mu \mathrm{m}) \\
\text { Diamétro base }(\mu \mathrm{m})\end{array}$ & $\begin{array}{l}20-45 \\
90-95\end{array}$ & $\begin{array}{c}20-40 \\
99-103\end{array}$ & $\begin{array}{c}15-60 \\
95-100\end{array}$ \\
\hline $\begin{array}{l}\text { ESPORANGIOS: } \\
\text { Largo }(\mu \mathrm{m}) \\
\text { Ancho }(\mu \mathrm{m}) \\
\text { Diám. Zoosporas }(\mu \mathrm{m})\end{array}$ & $\begin{array}{l}200-550 \\
40-65 \\
15-25\end{array}$ & $\begin{array}{r}150-500 \\
18-70 \\
18-21\end{array}$ & $\begin{array}{l}150-450 \\
20-70 \\
19-21\end{array}$ \\
\hline $\begin{array}{l}\text { CLAMIDOSPORAS: } \\
\text { Generan }\end{array}$ & $\begin{array}{l}\text { Abundantes } \\
\text { Oogonios- } \\
\text { Esporangios }\end{array}$ & $\begin{array}{c}\text { Escasas } \\
\text { No-observado }\end{array}$ & $\begin{array}{c}\text { Abundantes } \\
\text { Oogonios- } \\
\text { Esporangios }\end{array}$ \\
\hline $\begin{array}{l}\text { OOGONIOS: } \\
\text { Largo }(\mu \mathrm{m}) \\
\text { Ancho }(\mu \mathrm{m})\end{array}$ & $\begin{array}{r}75-270 \\
50-110\end{array}$ & $\begin{array}{l}40-278 \\
40-150\end{array}$ & $\begin{array}{l}30-300 \\
30-85\end{array}$ \\
\hline $\begin{array}{l}\text { OOSPORAS: } \\
\text { Tipo } \\
\text { Diámetro }(\mu \mathrm{m})\end{array}$ & $\begin{array}{c}\text { Céntricas- } \\
\text { Subcéntricas } \\
26-30 \\
\end{array}$ & $\begin{array}{c}\text { Céntricas- } \\
\text { Subcéntricas } \\
17-35 \\
\end{array}$ & $\begin{array}{c}\text { Céntricas } \\
\text { Subcéntricas } \\
18-30 \\
\end{array}$ \\
\hline ANTERIDIO: & $\begin{array}{c}\text { Diclino } \\
\text { Androgino }\end{array}$ & $\begin{array}{c}\text { Diclino- } \\
\text { Monoclino } \\
\text { Andro-Hipogino }\end{array}$ & $\begin{array}{c}\text { Diclino- } \\
\text { Monoclino } \\
\text { Androgiato }\end{array}$ \\
\hline $\begin{array}{l}\text { PROD. OOGONIOS A: } \\
10^{\circ} \mathrm{C} \\
20^{\circ} \mathrm{C}\end{array}$ & $\begin{array}{l}\text { Abundante } \\
\text { Regular }\end{array}$ & $\begin{array}{l}\text { Abundante } \\
\text { Abundante }\end{array}$ & $\begin{array}{c}\text { Abundante } \\
\text { Escaso }\end{array}$ \\
\hline $\begin{array}{l}\text { CAPACIDAD INFECTIVA } \\
\text { CRECIMIENTO A } 30^{\circ} \mathrm{C}\end{array}$ & $\begin{array}{c}\text { Baja } \\
\text { Presente }\end{array}$ & $\begin{array}{c}\text { Nula } \\
\text { Presente }\end{array}$ & $\begin{array}{c}\text { Alta } \\
\text { Presente }\end{array}$ \\
\hline
\end{tabular}

patógeno $(100 \%)$. Las cepas saprotrofas con morfología regular se diferenciaron de las biotrofas en su poder patógeno $(100 \%$ de patogenicidad, y un $87,5 \%$ de mortalidaden los peces de $10 \mathrm{~g}$ ), mientras que en los de 100 $\mathrm{g}$ sólo se observó la presencia de hifas (sin mortalidad). Estas diferencias en la patogenicidad de las cepas tambićn ha sido observada por Hatai y Hoshiai (1993), quienes al infectar salmón coho de 20 y $30 \mathrm{~g}$ con 2 cepas de Suprolegnia, observaron que una de ellas (Saprolegnia parasitica $\mathrm{H} 2$ ). era altamente patógena, provocando un $100 \%$ de mortalidad a los 10 días de iniciado el ensayo. La otra cepa, que estudiaron. Saprolegnia diclina (H3), infectó al $70 \%$ de los peces. sin que se obscrvaran mortalidades. la mayoria de los peces infectados se recuperaron al cabo de 12 dias, demostrando asi el bajo poder patógeno de esa cepa.

Independientemente de su origen, las cepas aisladas en la piscicultura de Río Blanco, entre abril y marzo 1996 , fueron capaces de crecer a $30^{\circ} \mathrm{C}$, aunque con diferentes tasas de crecimiento. Estos resultados concuerdan con los trabajos de Hatai y Hoshiai $(1992,1993)$ quienes al cultivar + cepas de $S$. parasitica y una de $S$. diclina encontraron que todas ellas presentaron similares tasas de crecimiento a 10,20 y $25^{\circ} \mathrm{C}$, sin embargo, en los cultivos a $30^{\circ} \mathrm{C}$ solo crecieron las cepas de $S$. parasitica. Dieguez-Uribeondo et al.(1996), también concluyeron que las cepas de $\boldsymbol{S}$. parasitica biotrofas en salmones, presentaban la capacidad para crecer a $30^{\circ} \mathrm{C}$, mientras que cepas saprotrofas de $S$. diclina no lo hacian. En un estudio 


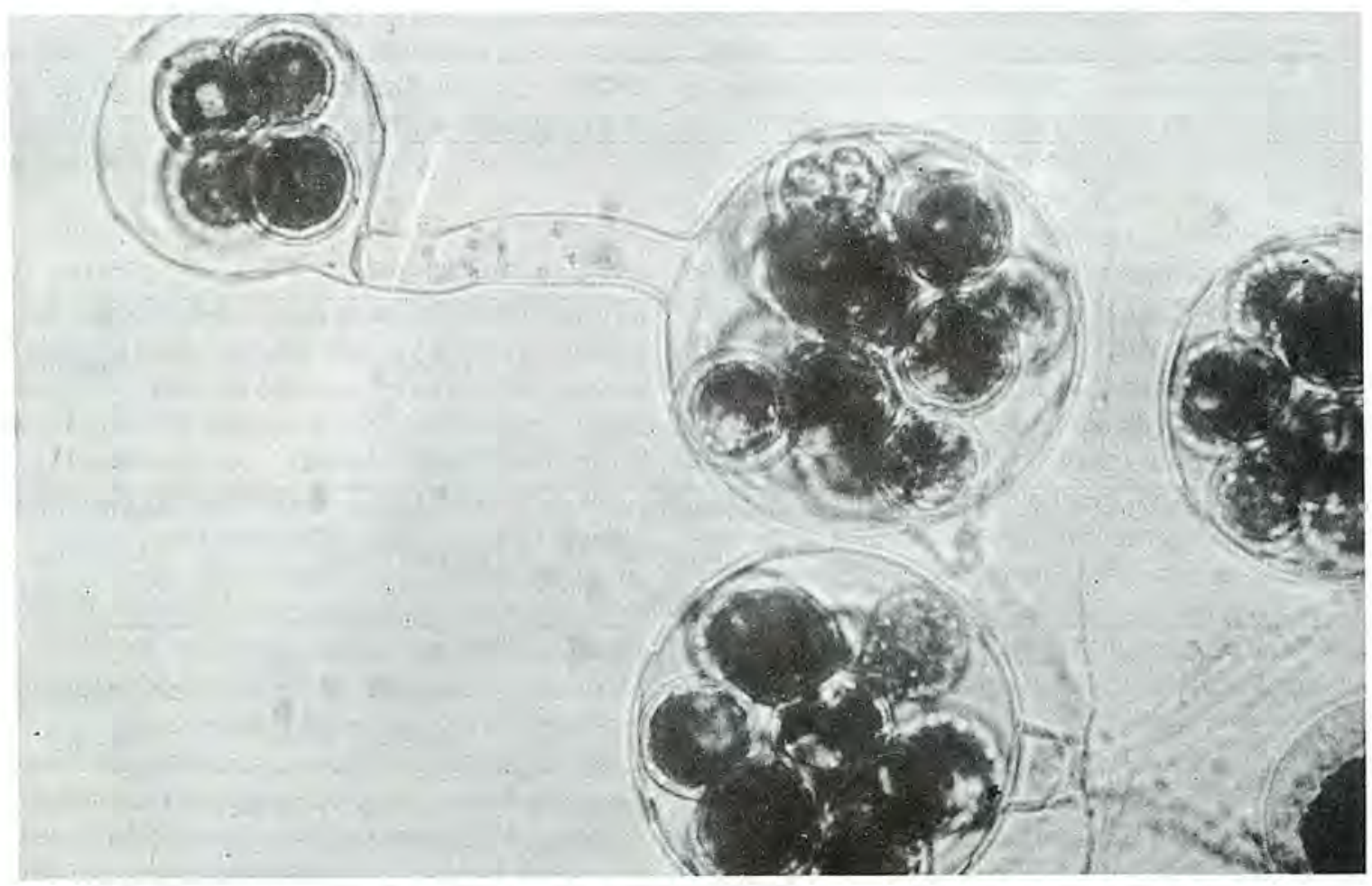

Fig.2. Microcaracterísticas de Saprolegnia parasitica, oogonios y oosporas céntricas 1000X

para establecer la especificidad con respecto al huésped, Hatai et al (1990) encontraron que de 17 cepas de Saprolegnia aisladas desde pisciculturas japonesas, sólo las cepas patógenas de trucha arcoiris podían crecer a $30^{\circ} \mathrm{C}$. Lo anterior nos sirvió como carácter concluyente para la identificación de las cepas aisladas en este estudio.

Uno de los problemas que se generan en el estudio de hongos acuáticos causantes de saprolegniosis, es la identificación de las especies, principalmente debido a que no existe una clara delimitación de éstas. En la literatura, manuales de ictiopatología y revistas de divulgación (Kinkelin et al, 1985), se encuentra que la saprolegniosis se atribuye principalmente a $S$. parasítica, lo que no siempre se puede comprobar, debido a que muchas de las cepas aisladas a partir de peces infectados no forman órganos sexuales, a menos que se mantengan durante largo tiempo en medios especiales (Willoughby, 1978).

La mayoria de los autores que han estudiado las formas sexuales de Saprolegnia le han asignado nombres especificos, por Ej. Seymur (1970) en un estudio sobre el género transfirió a sinonimia a muchas de las especies antes descritas, reclasificando 28 como pertenecientes a $S$. ferax y otras 13 como $S$. diclina. Neish (1977), sugiere que $S$. parasítica puede ser considerada como sinónimo de $S$. diclina.
Por otro lado debido a que las estructuras sexuales de $S$. parasítica son morfológicamente similares a las de las cepas saprotrofas de $\boldsymbol{S}$. diclina, diversos autores (Neish, 1977; Singhal et al, 1987; Ogbonna y Alabi, 1992; Bullis y Noga, 1990), han optado por utilizar el término Complejo Saprolegnia para identificar el agente causal de la saprolegniosis de peces y sus huevos. Los hongos pertenecientes a este complejo se caracterizan principalmente por ser sapro o biotrofos, con capacidad para generar estructuras reproductivas en pocas semanas al ser cultivadas en semillas de cáñamo a $10^{\circ} \mathrm{C}$, presentar oosporas céntricas o subcéntricas, muchas de las cuales abortan antes de germinar y por presentar anteridios diclinos o monoclinos. Estos caracteres coinciden con los encontrados en las cepas aisladas lo que nos permitió establecer que el agente causal de las micosis que afectan a las truchas arcoirisy sus huevos en la piscicultura de Río Bíanco pertenecen a este complejo.

En 1978, Willoughby reconsideró el uso del concepto "Complejo Saprolegnia" indicando que el agente causal de estas micosis en peces corresponde a $\boldsymbol{S}$. diclina, subdividiendo la especie aislada desde el lago Windermare (Inglaterra) en tres tipos: $\boldsymbol{S}$. diclina tipo I, considerada como parásito específico de salmones, $\boldsymbol{S}$. diclina tipo II parásito de percas y $\boldsymbol{S}$. diclina tipo III, únicamente saprotrofo. No obstante, Hatai y Hoshiai, (1993) conside- 
ran que en los salmones, especialmente en época de reproducción, la saprolegniosis se debe a un solo tipo de Saprolegnia o bien a un grupo estrechamente ligado, que corresponde a $\boldsymbol{S}$. parasitica (Coker).

$\mathrm{El}$ análisis de las características morfofisiológicas y patogénicas de las cepas aisladas, nos hizo pensar que estas podrian pertenecer a las especies $\boldsymbol{S}$. parasitica y $\boldsymbol{S}$. diclina, sin embargo cuando se realizó la prueba de crecimiento a $30^{\circ} \mathrm{C}$, se pudo concluir que estas correspondían a cepas con diferentes grados de patogenicidad pertenecientes al taxa Saprolegnia parasitica Coker.

\section{AGRADECIMIENTOS}

Se agradece a los Drs. H. Cerisola, P.Garcia -Tello y E.Piontelli, por la guia durante el desarrollo de esta investigación y la revisión crítica de este manuscrito.

\section{REFERENCIAS}

Beakes, G. \& Burr, A.W. (1983). Aquatic fungi: Zoospores and encystement, with particular reference to saprolegnian Oomycetes. J. Appl.Aquacult.3:35-50

Bernal,F. (1996). Eficacia de distintos tratamientos para controlar hongos (Saprolegnia) en un sistema de incubación en la piscicultura de Rio Blanco, Tesis para optar al titulo de Ingeniero Pesquero. Escuela de Ciencias del Mar. Universidad Católica de Valparaiso.

Bruno, B. \& Stamps, S. (1987). Saprolegniosis of Allantic salmon, Salmo salar L. fry. Journal Fish Dis. 10:513-517

Bullis, R. \& Noga, J.E. (1990). Immunological relationship of the Fish Pathogenic Oonycete Saprolegnia parasitica to other Oomycetes and unrelated fungi, Journal of Aquatic Animal Health 2:223-227

Chien, C.Y. (1981). Observations on the growt h and Morphology of saprolegniaceous Fungi isolated from rainbow trout (Salmo gairlneri). Fish Pathology 15: 241-247

Chien, C.Y., (1987). Some water molds isolated from rainbow trout (Salmo gairneri) associated with fish saprolegniosis. The memoir of parasitology in fish disease 2 : 99-105

Conroy, D. A.\& Hernandez, (1989). A review on the main infections and parasitic diseases of fish of the genus Colossoma. Ed. BogotaColombia/Rede-Regional-Entidades y Centros de Acuicultura de America Latina, pp. 93-112

Dieguez-Uribeondo, J., Cerenius L \&.Siderhll, (1994). Saprolegnia parasitica and its virulence on three different species of fres water crayfish. Aquaculture, 120: 219-228

Dieguez-Uribeondo, J., Cerenius L \&.Siderhll. (1996). Physiological characterization of Saprolegnia parasitica isolates from brown trout, Aquaculture, 140:247-257

Figueida, L. B. \& Ceccarelli, P.S. (1991). Observations about the ectoparasites present in tropical island piscicultures (CEPTA and surroundings). Bol.Tec, CEPTA. 4:58-6

Gajiluesek, J. \& Rubcov, V. (1985), Microestructure of moulted carp eggs infested with Saprolegnia. Folia-Zool, BRNO. 34: 349-355

Hatai, K., Willoughby, L \& Beakes C. ( 1990 ). Some characteristies of Saprolegnia obtained from fish hatcheries in Japan. Mycol-Res. 94: 182190
Ifatai, K. \&. Hoshiai, G. (1992) (a). Saprolegniosis in Cultured Coho salmon Oncorlynchus kisutch. Gyobyo Kenkyu, 27:233-234

Hatai, K. \& Hoshiai,G. (1992) (b). Mass mortality in cultured coho salmon (Oncorly'nchus kisutch) due to Saprolegnia parasitica Coker. J. of Wildlife Diseases 28:532-436

Hatai, K. \& Hoshiai, G. (1993). Characteristics of two Saprolegnia species isolated from Colio Salmon with saprolegniosis, Joumal of Aquatic Animal Health 5:115-118

Helena, D.1(994). Control de hongos (Saprolegnia) en huevos de trucha arcoiris, Oncorhynchus mykiss, mediante el uso de soluciones salinas. Tesis para optar al titulo de Ingeniero Pesquero. Escuela Ciencias del Mar. Universidad Católica de Valparaiso.

Herrera, T, \& Uiloa, M. (1990). El reino de loshongos, micologia básica yaplicada. Fondo de Cultura Económica, Universidad Nacional Autónoma de México, México, D.F.

Hubert, M.F. (1982). Là saprolegniose des salmonides etude in vitro de 43 antifungiques. These, L'Institt National Polytechnique de Toulouse, France.

Kinkelin, P., Michel,P.\&Ghittino,P.(1985). Tratndo de lasenfermedades de Ios peces, Editorial Acribia, S.A. Zaragosa.

Larsteva, L.V.\& Dudka,L.A. (1990). Dependence of the development of Suprolegniaceae on the reproductive quality of the eggs of the sturgeon and white salmon. Mikologiya y Fitopatologiya 24:112-116

Mendoza, J., (1994). Efecto de la alta densidad de incubación, con y $\sin$ antifüngicos, sobre la mortalidad de ovas verdes de truch a arcoirisvariedad Donaldson. Memoria de titulo presentada a la facultad de medicina veterinaria de la Universidad de Concepción para optar al titulo de Médico Veterinario, Chillán-Chile.

Neish, G. (1977). Observations on saprolegniaisis of adult sockeye salmon, Oncorhynchus nerka Walthaum. J. Fish Biol. 10:513-522

Ogbonna, C. I .\& Alabi,R.O. ( 1991), Studies on species of fungi associated with mycotic infections of fish in a Nigerim fresivater fish pond. Hidrobiologia 220:131-135

Papatheodorou, V., (1981), Observations sur Saprolegnia australis Elliot, agent pathogene de la saprolegniose des poissons. Bulletin Francais de pisciculture. 283:96-101 
Papatheodorou, V., Labat, R. \& Quillier, R.(1981). Ichtyomycoses des salmonidae importance de Saprolegnia diclina Humphrey (Saprolegniaceae, Saprolegniales, Oomycetes). Extrait du bulletin de la societe d'histoire nafurelle de Toulouse 117: 8-10

Puckeridge, J. (1991). Epidemics in a Murray fish, SAFISH. 116:12-14

Rand, T.G. \& Munden, D. (1992). Enzyme involvement in the invasion of brook char Salvelinus fontinalis, eggs by Saprolegnia diclina (Oomycotina: Saprolegniaceae). J. Fish Disease 19:91-94

Rand, T.G. \& Munden, D. (1993 a). Envolvement of zoospores of Saprolegnia diclina (Oonycotina: Saprolegniaceate) in the attachement to and invasion of eggs of Brook Trout under experimental conditions. Journal of Aquatic Animal Health 5: 233-239

- Rand, T.G. \& Munden, D.1993 b, Chemotaxis of zoospores of two fish egg-pathogenic strains of Saprolegnia diclina (Oomycotina: Saprolegniaceae) toward Salmonid egg chorion extracts and selected amino acids and sugars. Journal of Aquatic Animal Health 5: 240-245

Richards, R.H. \& Pickering, A.D. (1978). Frequency and distribution patterns of Saprolegnia infection in wild and hatchery reared brow trout Salmo trutta and char Salvelinus alpinus (L.), Joumal of Fish Diseases. 1: $69-82$

Scott, W. \& O'Bier, A. (1962). Aquatic fungi associated with diseased fish and fish eggs, the Progressive Fish-Culturist, 24: 3-15

Seymur, R. L. (1970). The genus Saprolegnia. Nova Herwigia, 19:1124
Singhal,R.N.,Jeet, S. \& Davies, R.W. (1987). Experimental trạ̣smission of Saprolegnia and Achly'a to fish. Aquaculture. 64: 1-7

Timejko, V.N. (1992). Depletion of glycogen reserves in saprolegniosis aflected developing eggs of salmon, Salmo salar. Vopr-lkhtiol. J. Ichthyol. 32:186-190

Willoughby, L. G. (1978). Saprolegnias of salmonid fish in Windermere: a critical analysis. Joumal of Fish Disease. 1:51-67

Wood, S.E., Willougby, L.G. \& Beakes, G. (1986). Preliminary evidence for inhibition of Saprolegnia fungus in the mucus of brown trout, Salmo trutta L, following experimental challenge. J. Fish. Dis. 9:557-560

Xu, D., Rogers, W.A. \& Rushing, A.E. (1990). Ultrastructure of the hyphate of Saprolegnia parasitica. Journal of Aquatic Animal Health 2:289-294

Xu, D. \& Rogers, WV.A. (1991). Electron microscopy of infection by Saprolegnia spp. in Channel Caffish. Joumal of Aquatic Animal Health 3:63-69

Yuasa, K. \& Hatai, K. (1994). An attempt of classification by biological characteristics of some pathogenic water moulds from freswater fishes. Reprinted from Nippon Kingakukai Kaiho 35: 104-110 